Quim. Nova, Vol. 35, No. 3, 608-611, 2012

\title{
DESENVOLVIMENTO E VALIDAÇÃO DE MÉTODO ANALÍTICO PARA QUANTIFICAÇÃO DO FÁRMACO BEVACIZUMABE POR CROMATOGRAFIA A LÍQUIDO DE ALTA EFICIÊNCIA
}

\author{
Elionai Cassiana de Lima Gomes e Armando da Silva Cunha Júnior* \\ Faculdade de Farmácia, Universidade Federal de Minas Gerais, Av. Antônio Carlos, 6627, 31270-901 Belo Horizonte - MG, Brasil \\ Maria Irene Yoshida \\ Departamento de Química, Instituto de Ciências Exatas, Universidade Federal de Minas Gerais, Av. Antônio Carlos, 6627, \\ 31270-901 Belo Horizonte - MG, Brasil \\ Rodrigo Jorge \\ Faculdade de Medicina de Ribeirão Preto, Universidade de São Paulo, Av. Bandeirantes, 3900, 14049-900 Ribeirão Preto - SP, Brasil \\ Recebido em 2/5/11; aceito em 25/8/11; publicado na web em 30/9/11

\begin{abstract}
DEVELOPMENT AND VALIDATION OF AN ANALYTICAL METHOD FOR QUANTITATION OF THE DRUG BEVACIZUMAB BY HIGH PERFORMANCE LIQUID CHROMATOGRAPHY.In this study, an analytical method was developed and validated for quantitation of the drug bevacizumab $\left(\right.$ Avastin $^{\circledR}$ ) by high performance liquid chromatography (HPLC). The HPLC column was a BioSuite $250^{\oplus}$ HR SEC, $300 \times 7.8 \mathrm{~mm}$ x $5 \mu \mathrm{m}$ (Waters, USA). The mobile phase consisted of phosphate buffered saline (PBS). The results revealed that the method was specific, precise, accurate, robust and linear $\left(\mathrm{r}^{2}=0.998\right)$ from 5 to $75 \mu \mathrm{g} \mathrm{mL} \mathrm{m}^{-1}$. Therefore, this method can be used in drug release studies or in quality control ampoules of the drug.
\end{abstract}

Keywords: bevacizumab; high performance liquid chromatography; validation.

\section{INTRODUÇÃO}

O bevacizumabe (Avastin ${ }^{\circledR}$ ) é um anticorpo monoclonal humanizado, produzido por tecnologia de DNA recombinante em um sistema de expressão em célula de mamífero, de ovário de hamster chinês, em um meio nutriente contendo o antibiótico gentamicina e é purificado por um processo que inclui a inativação viral específica e etapas de remoção. Esse anticorpo é constituído por 214 aminoácidos e tem massa molecular de aproximadamente $149 \mathrm{kDa}$. O bevacizumabe foi aprovado pelo FDA (Food and Drug Administration) em fevereiro de 2004 e em janeiro de 2005 pela EMEA (European Agency for the Evaluation of Medicinal Products) para uso no tratamento de câncer colorretal.

O mecanismo de ação do bevacizumabe baseia-se na sua ligação ao fator de crescimento do endotélio vascular (VEGF, vascular endothelial growth factor, um dos principais agentes que estimulam a formação de novos vasos), inibindo desta forma a ligação do VEGF aos seus receptores na superfície das células endoteliais. A neutralização da atividade biológica do VEGF diminui a vascularização, o que, no caso de tumores, causa a diminuição ou supressão do crescimento. ${ }^{1}$

Devido ao seu efeito inibidor da angiogênese, o fármaco vem sendo utilizado não só no tratamento de diversos tipos de câncer, mas também em doenças oculares decorrentes da angiogênese excessiva, tais como a Retinopatia Diabética Proliferativa e a Degeneração Macular Relacionada à Idade. ${ }^{2}$ Seu uso off-label em tais doenças já é prática comum dentro dos consultórios de oftalmologia em diversos países, inclusive o Brasil. Como é necessária a aplicação diretamente no local de ação, o fármaco é administrado no interior do bulbo do olho por meio de injeções intravítreas. ${ }^{1}$ São requeridos entre 150 e $300 \mu \mathrm{L}$ do medicamento em cada injeção, o que torna prática comum pelos médicos o fracionamento da ampola de Avastin ${ }^{\circledR}$, já que a mesma contém originalmente $4 \mathrm{~mL}$ do medicamento. Assim, é fundamental o desenvolvimento de um método analítico seletivo e de alta sensibilidade que permita a quantificação do fármaco para avaliar a qualidade dos produtos fracionados e, também, possibilitar

*e-mail: armando@ufmg.br o desenvolvimento de novos sistemas de administração.

A maioria dos trabalhos descritos na literatura utilizam ELISA (Enzyme Linked Immuno Sorbent Assay) para a quantificação do bevacizumabe, uma técnica cara e de difícil aplicação em rotina analítica. ${ }^{3-8}$ Poucos são os trabalhos que utilizam CLAE para a quantificação do fármaco e, quando o fazem, não há informações claras em relação ao desenvolvimento do método. ${ }^{9,10} \mathrm{O}$ presente trabalho teve por objetivo o desenvolvimento e a validação de método analítico para doseamento do fármaco utilizando cromatografia líquida de alta eficiência (CLAE), uma técnica mais simples e mais econômica.

Foi escolhida a cromatografia por exclusão de tamanho, uma vez que as técnicas mais utilizadas em CLAE (cromatografia em fase normal e reversa) utilizam solventes orgânicos para ajuste da polaridade da fase móvel, como acetonitrila e metanol, o que causaria a desnaturação do fármaco.

A validação foi realizada de acordo com a Resolução no 899/2003 da Agência Nacional de Vigilância Sanitária (ANVISA). ${ }^{11}$

\section{PARTE EXPERIMENTAL}

\section{Material e equipamentos}

Foram utilizados os seguintes compostos: Avastin ${ }^{\circledR}(25 \mathrm{mg} / \mathrm{mL}$, ampola de $4 \mathrm{~mL}$ ); água purificada obtida em sistema Milli-Q para uso em CLAE; fosfato de potássio monobásico anidro; fosfato de sódio monobásico anidro; fosfato de sódio dibásico anidro; fosfato de sódio dibásico hepta-hidratado; cloreto de sódio; D-(+)-trealose; Tween 20.

Para as análises foram utilizados: espectrofotômetro Hewlett Packard HP 8453; cromatógrafo Waters (bomba Waters 515 e autoinjetor Waters 717) acoplado a detector Waters 486 UV-VIS; coluna Waters - BioSuite 250, $5 \mu \mathrm{m}$, HR SEC (7,8 x $300 \mathrm{~mm})$.

\section{Método}

Desenvolvimento do método analítico

Primeiramente foi realizada uma varredura do fármaco na região 
do ultravioleta em espectrofotômetro HP 8453. Uma amostra de bevacizumabe foi diluída em solução salina tamponada $\mathrm{pH}$ 7,4 até uma concentração final de $25 \mu \mathrm{g} / \mathrm{mL}$, sendo a varredura programada em uma faixa entre 200 a $400 \mathrm{~nm}$, com o objetivo de se determinar o comprimento de absorvância máxima do fármaco.

Foram testadas duas soluções como fases móveis. A primeira, constituída de tampão fosfato de sódio $\mathrm{pH} 7,4$, foi preparada com 1,2 $\mathrm{g}$ de fosfato de sódio monobásico anidro e 13,4 g de fosfato de sódio dibásico hepta-hidratado, diluídos em água purificada até um volume final de $1000 \mathrm{~mL}$. O pH final foi ajustado com fosfato de sódio monobásico anidro.

A segunda solução testada como fase móvel, solução salina tamponada $\mathrm{pH} 7,4$, foi preparada com $2,38 \mathrm{~g}$ de fosfato de sódio dibásico anidro, $0,19 \mathrm{~g}$ de fosfato de potássio monobásico anidro e 8,00 g de cloreto de sódio, diluídos em água purificada até um volume final de $1000 \mathrm{~mL}$. O pH final foi ajustado com fosfato de potássio monobásico anidro.

Com o objetivo de redução de custo e de tempo de análise, foram avaliados três diferentes fluxos para a fase móvel $(0,5 ; 0,8$ e $1,0 \mathrm{~mL} / \mathrm{min})$.

\section{Validação do método analítico}

Todo método desenvolvido e não descrito em farmacopeia ou formulários oficiais deve ser validado, sendo avaliados os seguintes parâmetros: especificidade, intervalo, linearidade, limite de detecção, limite de quantificação, precisão, exatidão e robustez. ${ }^{11}$

\section{Parâmetros avaliados}

A especificidade do método foi testada analisando-se uma amostra de solução salina tamponada pH 7,4 contendo as substâncias presentes na formulação do medicamento nas concentrações indicadas pelo fabricante: $60 \mathrm{mg} / \mathrm{mL}$ de D-(+)-trealose e $0,4 \mu \mathrm{g} / \mathrm{mL}$ de Tween 20 (polissorbato 20 ou monolaurato de polioxietileno 20 sorbitano).

A avaliação da linearidade foi realizada a partir da média de 3 curvas analíticas obtidas em 3 dias consecutivos, nas concentrações de 5 (limite inferior do intervalo), 10, 25, 50 e 75 (limite superior do intervalo) $\mu \mathrm{g} / \mathrm{mL}$ de bevacizumabe. Para cada dia foi utilizado um lote diferente do medicamento, totalizando três lotes de produção ao final dos três dias de análise. Todas as amostras foram diluídas em solução salina tamponada $\mathrm{pH}$ 7,4 até a concentração final desejada, filtradas em membrana 0,45 $\mu \mathrm{m}$ de poro (Durapore, Millipore ${ }^{\circledR}$ ) e injetadas em triplicata no cromatógrafo, registrando-se os valores das áreas. Os resultados foram tratados estatisticamente pelo método dos mínimos quadrados, obtendo-se a regressão linear. Ainda como resultado da avaliação da linearidade do método, foram calculados os limites de detecção e de quantificação, por meio da divisão entre o desvio padrão dos coeficientes lineares das três curvas analíticas do ensaio de linearidade pela média dos coeficientes angulares das curvas, multiplicados por 3,0 e 10,0, respectivamente. ${ }^{11}$ Para o estudo da robustez foram avaliadas a variação de fluxo $(0,99$ a $1,01 \mathrm{~mL} / \mathrm{min})$ e de $\mathrm{pH}$ da fase móvel $(7,0$ a 7,8).

A precisão foi avaliada em dois níveis: precisão intracorrida (repetitividade) e precisão intercorridas (precisão intermediária). Para a repetitividade, cinco soluções com concentrações diferentes $(5$, $10,25,50$ e $75 \mu \mathrm{g} / \mathrm{mL}$ ) foram injetadas em triplicata, totalizando 15 determinações, sendo o resultado da análise expresso em termos de desvio padrão relativo (DPR). A precisão intermediária foi avaliada do mesmo modo, porém as análises foram realizadas em três dias diferentes, totalizando 45 determinações.

A exatidão foi definida preparando-se as amostras até a obtenção de quatro concentrações utilizadas para a construção da curva analítica utilizada no teste de linearidade, considerando-se que o método é exato quando há proximidade dos resultados obtidos em relação ao valor verdadeiro. Foi utilizada a concentração declarada nas ampolas de Avastin ${ }^{\circledR}$ como referência.

Além disso, foi feita uma avaliação da estabilidade do fármaco. O bevacizumabe foi diluído em solução salina tamponada $\mathrm{pH}$ 7,4 até uma concentração final de $50 \mu \mathrm{g} / \mathrm{mL}$ e a amostra foi colocada em incubadora mantida a $37^{\circ} \mathrm{C}$ por 7 dias. Em tempos pré-determinados, foram retiradas alíquotas desta amostra, que foram analisadas por CLAE.

\section{RESULTADOS E DISCUSSÃO}

\section{Desenvolvimento do método analítico}

Os primeiros relatos da utilização do Avastin ${ }^{\circledR}$ (bevacizumabe) por meio de injeção intravítreo no tratamento de doenças da coroide e da retina datam de agosto de $2005 .{ }^{12,13}$ A partir dessa data, a utilização intravítreo do medicamento se tornou uma prática comum em vários países. Mas esse procedimento requer o fracionamento da ampola do Avastin ${ }^{\circledR}$, já que nessa via de administração a dose requerida do fármaco é entre 200 a 400 vezes menor que a utilizada por via sistêmica. Até o momento, apenas Bakri e colaboradores ${ }^{4}$ realizaram estudos de estabilidade com o Avastin ${ }^{\circledR}$. O método de quantificação desenvolvido por esses autores, apesar de dispendioso e de difícil aplicação em rotina analítica, tem sido o mais adotado nos mais diferentes tipos de estudo empregando o bevacizumabe.

De acordo com o espectro de varredura feito na região do ultravioleta, o comprimento de onda de maior absorção do fármaco encontrado foi $279 \mathrm{~nm}$ e, portanto, esse foi o comprimento de onda selecionado para as análises em CLAE.

As fases móveis testadas foram compostas exclusivamente por tampão, uma vez que o uso de solventes orgânicos poderia desnaturar o fármaco. O primeiro tampão testado (tampão fosfato de sódio $0,1 \mathrm{M} \mathrm{pH} 7,4)$ não apresentou viabilidade para ser utilizado como fase móvel, pois apresentou uma alta absorvância em 279 nm e não houve uma boa resolução entre o pico referente ao tampão e o pico referente ao fármaco (Figura 1). Em seguida, foi testada solução salina tamponada $\mathrm{pH} 7,4$, que apresentou uma baixa absorvância no comprimento de onda selecionado (Figura 1) e não interferiu no pico do fármaco. Dessa forma, esse tampão foi escolhido como fase móvel.

Após escolha do tampão a ser utilizado como fase móvel, foi feita a avaliação de diferentes fluxos de fase móvel (0,5;0,8 e 1,0 mL/min).

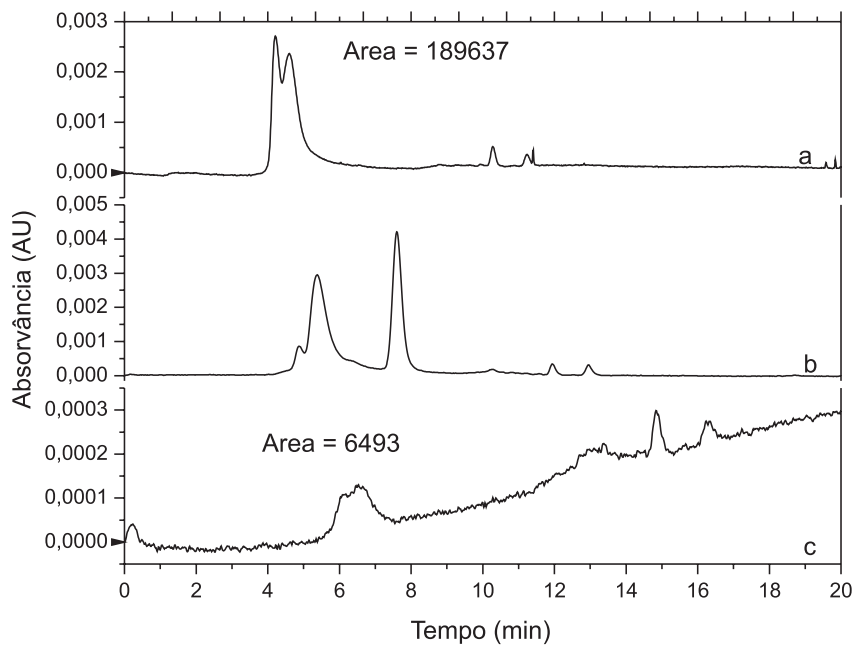

Figura 1. Cromatogramas das fases móveis testadas: (a) tampão fosfato de sódio 0,1 M pH 7,4, mostrando o valor da área do pico; (b) bevacizumabe $(50 \mu \mathrm{g} / \mathrm{mL}$ ) diluído em tampão fosfato de sódio $0,1 \mathrm{M}$; (c) solução salina tamponada $\mathrm{pH}$ 7,4, mostrando o valor da área do pico 
Foram considerados a simetria do pico e o tempo de retenção. Não houve alteração na simetria dos picos quando o fluxo é alterado. Dessa forma, o fluxo de 1,0 $\mathrm{mL} / \mathrm{min}$ foi escolhido por proporcionar maior rapidez à análise, diminuindo o tempo de corrida de 28 (fluxo de $0,5 \mathrm{~mL} / \mathrm{min})$ para $15 \mathrm{~min}(1,0 \mathrm{~mL} / \mathrm{min})$. O tempo de retenção $\left(t_{\mathrm{R}}\right)$ do fármaco foi reduzido de 14,98 , referente ao fluxo de $0,5 \mathrm{~mL} / \mathrm{min}$, para 7,58 min, com fluxo de 1,0 mL/min (Figura 2).

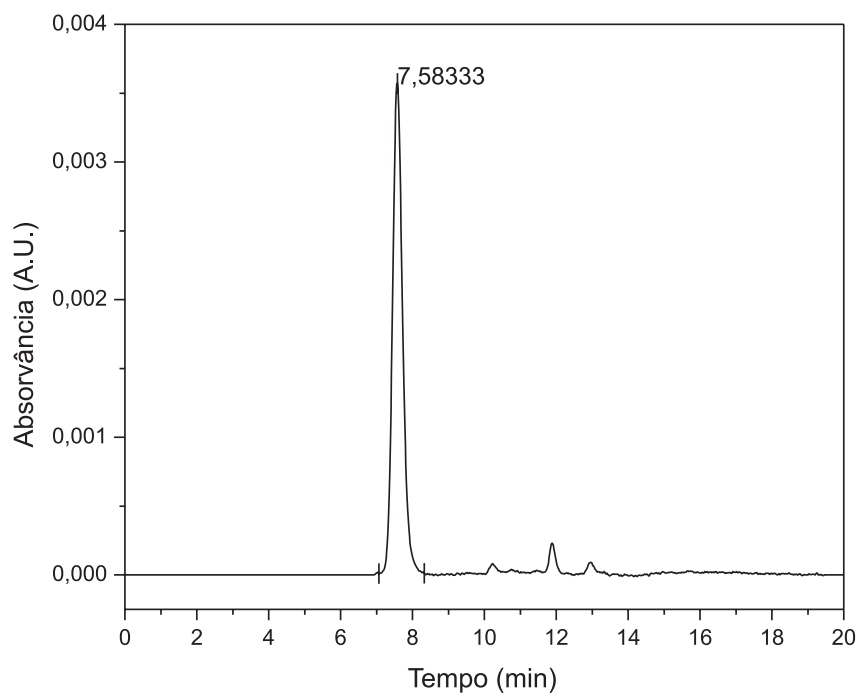

Figura 2. Cromatograma do bevacizumabe $(50 \mu \mathrm{g} / \mathrm{mL})$ em solução salina tamponada pH 7,4 com fluxo de 1,0 $\mathrm{mL} / \mathrm{min}$

O cromatograma obtido com o fluxo escolhido apresentou pico simétrico, com tempo de retenção curto, como demonstrado na Figura 2.

Durante o estudo, o volume de injeção foi fixado em $20 \mu \mathrm{L}$. Os parâmetros cromatográficos utilizados encontram-se no Quadro 1.

Quadro 1. Parâmetros cromatográficos utilizados para validação do método analítico

\begin{tabular}{|ll|}
\hline Parâmetro & Condição \\
\hline Detecção & UV $(\lambda=279 \mathrm{~nm})$ \\
Fluxo & $1,0 \mathrm{~mL} / \mathrm{min}$ \\
Coluna & Sílica, $7,8 \times 300 \mathrm{~mm}$, tamanho de partícula $5 \mu \mathrm{m}$ \\
Temperatura & $25^{\circ} \mathrm{C}$ \\
Fase móvel & Tampão PBS pH 7,4 \\
Volume de injeção & $20 \mu \mathrm{L}$ \\
Tempo de corrida & 15 min \\
\hline
\end{tabular}

\section{Validação do método analítico}

A seletividade ou especificidade foi o primeiro parâmetro avaliado para a validação do método analítico desenvolvido, uma vez que se a especificidade não for garantida, os outros parâmetros podem ser comprometidos. O método apresentou boa especificidade, pois não foram registrados picos no tempo de retenção do fármaco no cromatograma referente à solução salina tamponada $\mathrm{pH} 7,4$ contendo D-(+)-trealose na concentração de $60 \mathrm{mg} / \mathrm{mL}$ e $0,4 \mu \mathrm{g} / \mathrm{mL}$ de Tween (polissorbato) 20 (Figura 3).

A linearidade de um método demonstra que os resultados obtidos são diretamente proporcionais à concentração do fármaco na amostra, dentro de um intervalo especificado. ${ }^{14}$ Desse modo, o método proposto apresentou linearidade para o intervalo de concentrações entre 5 a 75 $\mu \mathrm{g} / \mathrm{mL}$, conforme equação da reta $\mathrm{Y}=1536 \mathrm{x}-2161$.

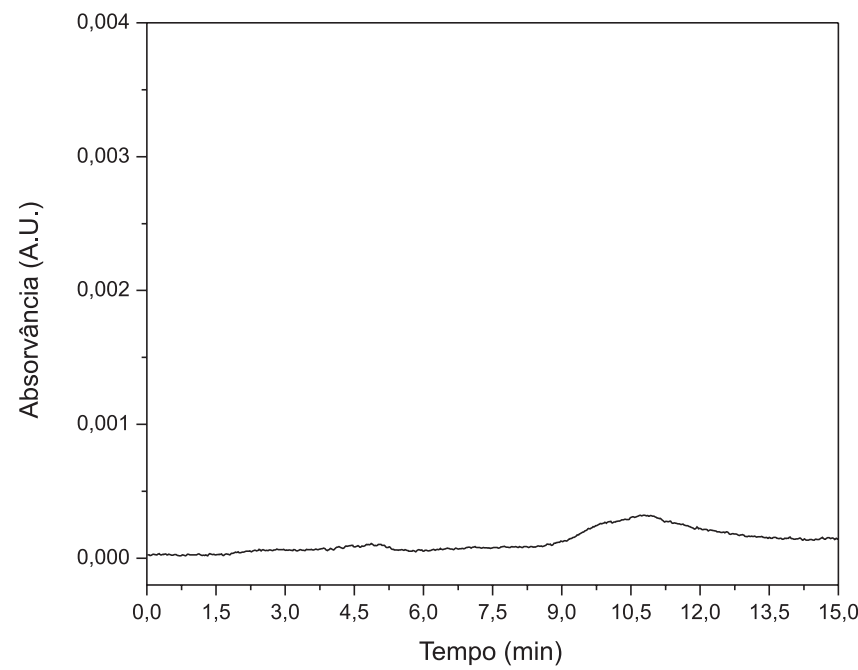

Figura 3. Cromatograma da amostra de solução salina tamponada $\mathrm{pH} 7,4$ contendo $60 \mathrm{mg} / \mathrm{mL}$ de D-(+)-trealose e e 0,4 $\mu \mathrm{g} / \mathrm{mL}$ de Tween 20 (polissorbato 20)

Por meio de análise de variância (ANOVA), verificou-se regressão linear significativa e desvio da linearidade não significativo $(\mathrm{p}<0,05)$. O coeficiente de determinação encontrado para a curva média foi de 0,9983, estando acima de 0,99, que é o valor mínimo aceitável pela RE 899/2003 da ANVISA (Tabela 1).

Tabela 1. Resultados do tratamento estatístico por análise de variância para a regressão linear

\begin{tabular}{lcccc}
\hline $\begin{array}{l}\text { Fonte de } \\
\text { variação }\end{array}$ & $\begin{array}{c}\text { Graus de liber- } \\
\text { dade }\end{array}$ & $\begin{array}{c}\text { Soma dos } \\
\text { quadrados }\end{array}$ & Variância & $\mathrm{F}$ \\
\hline Total & 14 & $2,432 \times 10^{10}$ & $1,737 \times 10^{9}$ & \\
Regressão & 1 & $2,428 \times 10^{10}$ & $2,428 \times 10^{10}$ & $12140,5^{*}$ \\
$\begin{array}{l}\text { Desvios da } \\
\text { regressão }\end{array}$ & 3 & 20000000 & 6666667 & 3,33 \\
Erro puro & 10 & 20000000 & 2000000 & \\
& $\begin{array}{c}\text { Estatística de } \\
\text { regressão e } \\
\text { coeficientes } \\
\mathrm{R}^{2}\end{array}$ & & & \\
Inclinação & 0.9983 & & & \\
Intercepto & 1536 & & & \\
\hline
\end{tabular}

* Valor significativo $(\alpha=0,05)$

Com os dados provenientes da avaliação da linearidade foram calculados os limites de detecção e de quantificação. Os valores obtidos foram 1,11 e $3,71 \mu \mathrm{g} / \mathrm{mL}$, respectivamente.

A robustez de um método analítico mede sua suscetibilidade frente a pequenas variações que podem ocorrer durante as análises de rotina. ${ }^{15} \mathrm{O}$ método se mostrou robusto para variações de fluxo no intervalo proposto $(0,99$ a $1,01 \mathrm{~mL} / \mathrm{min})$. Porém, para as variações de $\mathrm{pH}$, no intervalo testado $(7,0$ a 7,8$)$, verificou-se que há diferença estatisticamente significativa nos valores de área obtidos em $\mathrm{pH} 7,0$ quando comparados aos obtidos em pH 7,4 ou 7,8. Em relação aos dois últimos, não houve diferença estatisticamente significativa entre as áreas obtidas $(\mathrm{p}<0,05)$. Os resultados estão descritos nas Tabelas 2 e 3. Sendo assim, recomenda-se o controle do $\mathrm{pH}$ para a utilização deste método, visto que pode haver erros nos resultados se o valor de $\mathrm{pH}$ não for mantido constante durante o estudo. 
Tabela 2. Robustez com relação à variação do fluxo. Médias com letras iguais são estatisticamente semelhantes a $5 \%$

\begin{tabular}{|c|c|c|c|c|c|c|c|}
\hline \multirow{2}{*}{$\begin{array}{c}\text { Fluxo } \\
(\mathrm{mL} / \mathrm{min})\end{array}$} & \multicolumn{5}{|c|}{ Concentração $(\mu \mathrm{g} / \mathrm{mL})$} & \multirow{2}{*}{ Média } & \multirow{2}{*}{$\mathrm{CV}$} \\
\hline & 1 & 2 & 3 & 4 & 5 & & \\
\hline 0,99 & 46,3 & 48,2 & 48,0 & 47,7 & 47,5 & $47,5^{\text {a }}$ & $1,57 \%$ \\
\hline 1,00 & 48,2 & 47,8 & 47,8 & 48,6 & 45,5 & $47,6^{a}$ & $2,54 \%$ \\
\hline 1,01 & 47,6 & 47,2 & 46,4 & 50,0 & 47,2 & $47,7^{a}$ & $2,87 \%$ \\
\hline
\end{tabular}

Tabela 3. Robustez com relação à variação do pH. Médias seguidas de letras distintas diferem entre si estatisticamente pelo teste t de Student a 5\%

\begin{tabular}{|c|c|c|c|c|c|c|c|}
\hline \multirow{2}{*}{$\mathrm{pH}$} & \multicolumn{5}{|c|}{ Concentração $(\mu \mathrm{g} / \mathrm{mL})$} & \multirow{2}{*}{ Média } & \multirow{2}{*}{$\mathrm{CV}$} \\
\hline & 1 & 2 & 3 & 4 & 5 & & \\
\hline 7,0 & 38,0 & 35,9 & 36,8 & 37,8 & 36,5 & $37,0^{a}$ & $2,39 \%$ \\
\hline 7,4 & 49,8 & 46,4 & 48,6 & 49,0 & 50,7 & $48,9^{b}$ & $3,29 \%$ \\
\hline 7,8 & 51,4 & 50,4 & 50,2 & 51,0 & 49,6 & $50,5^{b}$ & $1,39 \%$ \\
\hline
\end{tabular}

Os resultados da repetibilidade e da precisão intermediária foram expressos em termos de desvio padrão relativo (DPR) (Tabela 4). Todos os valores de DPR obtidos, tanto para a precisão intracorrida quanto para a precisão intercorridas, encontram-se abaixo de 5\%, estando de acordo com o que preconiza a RE 899/2003 da ANVISA, o que evidencia repetibilidade e precisão intermediária adequadas para o método analítico em questão.

Tabela 4. Valores de desvio padrão relativo da avaliação da repetibilidade e da precisão intermediária do método analítico

\begin{tabular}{ccccc}
\hline \multirow{2}{*}{$\begin{array}{c}\text { Concentração } \\
(\mu \mathrm{g} / \mathrm{mL})\end{array}$} & Dia 1 & Dia 2 & Dia 3 & Interdias \\
\cline { 2 - 4 } 5 & 4,56 & 1,27 & 1,91 & 3,59 \\
10 & 4,87 & 1,27 & 2,91 & 3,38 \\
25 & 1,11 & 1,60 & 0,65 & 2,75 \\
50 & 1,81 & 0,59 & 1,72 & 2,21 \\
75 & 0,91 & 0,53 & 0,44 & 1,99 \\
\hline
\end{tabular}

No que diz respeito à exatidão, o método permitiu a recuperação de $99,66 \pm 2,37 \%$ para a concentração de $5 \mu \mathrm{g} / \mathrm{mL} ; 101,39 \pm 4,13 \%$ para $10 \mu \mathrm{g} / \mathrm{mL} ; 101,95 \pm 2,07 \%$ para $50 \mu \mathrm{g} / \mathrm{mL}$ e $99,79 \pm 2,17 \%$ para $75 \mu \mathrm{g} / \mathrm{mL}$, o que caracteriza o método como exato.

Por meio do estudo de estabilidade, verificou-se que a concentração de bevacizumabe atinge $94 \%$ da concentração inicial em 7 dias, em solução salina tamponada $\mathrm{pH} 7,4$ e temperatura de $37^{\circ} \mathrm{C}$. A estabilidade do medicamento é satisfatória, uma vez que o estudo de estabilidade foi conduzido em condições mais drásticas do que as condições em que o mesmo é armazenado (entre 2 e $6{ }^{\circ} \mathrm{C}$ ).

\section{CONCLUSÃO}

O método analítico proposto para detecção e quantificação do bevacizumabe por CLAE mostrou-se sensível, preciso e linear no intervalo de concentração entre 5 e $75 \mu \mathrm{g} / \mathrm{mL}$, sendo adequado para o controle de qualidade do medicamento ou estudos de desenvolvimento de sistemas de liberação farmacêutica com esse peptídeo. A estabilidade do fármaco em solução salina tamponada $\mathrm{pH}$ 7,4 é limitada, porém suficiente para a realização de análises normalmente conduzidas em rotina analítica.

\section{AGRADECIMENTOS}

À CAPES, pelo apoio financeiro.

\section{REFERÊNCIAS}

1. Rodrigues, E. B.; Farah, M. E.; Maia, M.; Penha, F. M.; Regatieri, C.; Melo, G. B.; Pinheiro, M. M.; Zanetti, C. R.; Prog. Retin. Eye Res. 2009, 28, 117.

2. Pandya, N. M.; Dhalla, N. S.; Santani, D. D.; Vascul. Pharmacol. 2006, $44,265$.

3. Sinapis, C. I.; Routsias, J. G.; Sinapis, A. I.; Sinapis, D. I.; Agrogiannis, G. D.; Pantopoulou, A.; Theocharis, S. E.; Baltatzis, S.; Patsouris, E.; Perrea, D.; Clin. Ophthalmol. 2011, 5, 697.

4. Bakri, S. J.; Snyder, M. R.; Reid, J. M.; Pulido, J. S.; Singh, R. J.; Ophthalmol. 2007, 114, 855.

5. Bakri, S. J.; Snyder, M. R.; Pulido, J. S.; Mccannel, C. A.; Weiss, W. T.; Singh, R. J.; Retina 2006, 26, 519.

6. Dib, E.; Maia, M.; Longo-Maugeri, I. M.; Martins, M. C.; Mussalem, J. S.; Squaiella, C. C.; Penha, F. M.; Magalhães Jr, O.; Rodrigues, E. B.; Farah, M. E.; Invest. Ophthalmol. Vis. Sci. 2008, 49, 1097.

7. Xu, L.; Zuch, C. L.; Lin, Y. S.; Modi, N. B.; Lum, B. L.; Cancer Chemother. Pharmacol. 2008, 61, 607.

8. Nomoto, H.; Shiraga, F.; Kuno, N.; Kimura, E.; Fujii, S.; Shinomiya, K.; Nugent, A. K.; Hirooka, K.; Baba, T.; Invest. Ophthalmol. Vis. Sci. 2009, 50, 4807.

9. Liu, L.; Ammar, D. A.; Ross, L. A.; Mandava, N.; Kahook, M. Y.; Carpenter, J. F.; Invest. Ophthalmol. Vis. Sci. 2011, 52, 1023.

10. Hsei, V.; DeGuzman, G. G.; Nixon, A.; Gaudreault, J.; Pharm. Res. 2002, 19, 1753.

11. Agência Nacional de Vigilância Sanitária (ANVISA); Resolução RE 899 de 29/5/2003 - Guia para validação de métodos analíticos e bioanalíticos, Diário Oficial da União, 2/6/2003, Brasília.

12. Rosenfeld, P. J.; Fung, A.E.; Puliafito, C. A.; Ophthalmic. Surg. Lasers Imaging 2005, 36, 336.

13. Rosenfeld, P. J.; Moshfeghi, A. A.; Puliafito, C. A.; Ophthalmic. Surg. Lasers Imaging 2005, 36, 331.

14. Lemos, G. S.; Santos, J. S.; Santos, M. L. P.; Quim. Nova 2010, 33, 1682.

15. Cassiano, N. M.; Barreiro, J. C.; Martins, L. R. R.; Oliveira, R. V.; Cass, Q. B.; Quim. Nova 2009, 32, 1021. 